\title{
QoS AND QoE ANALYSIS FOR VOICE AND DATA SERVICES OVER MOBILE NETWORKS
}

\author{
Mario Micić1 ${ }^{1}$ Toni Janevski \\ ${ }^{1}$ ZTE Corporation \\ ${ }^{2}$ Faculty of Electrical Engineering and Information Technologies, \\ "Ss. Cyril and Methodius" University in Skopje, \\ P.O. box 574, 1001 Skopje, N. Macedonia \\ tonij@ feit.ukim.edu.mk
}

\begin{abstract}
A b s t r a c t: The growing demand for a fast and cheap Internet access, especially via mobile devices, significantly changes the perception for the Internet services provided by the mobile operators. Easy access to the Internet "world" through the mobile technologies like LTE-Advanced provides full support of different types of services and applications which have strict requirements regarding network performance, bandwidth and speeds. This is a big challenge for the mobile operators in order to provide adequate support for all the users and various types of services. On the other hand, the users expect certain quality levels to be maintained. This paper describes and gives examples of the main QoE indicators measured from live mobile networks, how to optimize them and how to come close or achieve the apex of the current mobile networks performance.
\end{abstract}

Key words: QoE; QoS; mobile networks; user experience

\section{АНАЛИЗА НА КВАЛИТЕТОТ НА СЕРВИСОТ И КВАЛИТЕТОТ НА ИСКУСТВОТО ЗА ГОВОРНИ И ПОДАТОЧНИ СЕРВИСИ ПРЕКУ МОБИЛНИ МРЕЖИ}

\begin{abstract}
А п с т р а к т: Зголемената побарувачка за брз и евтин пристап до Интернет, особено преку мобилни уреди, значително ја менува перцепцијата за услугите на Интернет обезбедени од мобилните оператори. Лесниот пристап до „светот“ на Интернетот преку мобилните технологии како што е LTE-Advanced овозможува целосна поддршка на различни видови услуги и апликации кои имаат строги барања во врска со мрежните перформанси, ширината на опсегот и битските брзини. Ова е голем предизвик за мобилните телекомуникациски оператори со цел да се обезбеди соодветна поддршка за сите корисници како и разни видови услуги. Од друга страна, корисниците очекуваат да се одржат одредени нивоа на квалитет. Овој труд опишува и дава примери на главните индикатори QoE (Quality of Experience - квалитет на искуството) измерени на оперативни активни мобилни мрежи, како тие да се оптимизираат и како да се приближат или да го постигнат врвот на тековната изведба на мобилните мрежи.
\end{abstract}

Клучни зборови: квалитет на сервис; квалитет на искуство; мобилни мрежи; корисничко искуство

\section{INTRODUCTION}

Nowadays the users/people have become the instruments for measuring the quality and they have really high expectation regarding the performance of the networks, services and applications. The level of enjoying the use of a certain services by the endusers is referred to as Quality of Experience (QoE),
[1]. The QoE is a complex multidimensional composition, which can be observed from different points of view, where it can be based on subjective and objective methods.

The objective method is actually the technical and technology oriented concept (derived from the Quality of Service-QoS), it is based on the performance of the network and the provided services. In 
general, the QoS is just a subset of the QoE, so improvement of the QoS in the networks in many cases can lead to an improvement in the QoE, but not always. In the mobile wireless networks the mobility is one of the key factors to maintain quality of experience. However, also are very important the features and mechanisms for establishment, maintenance and continuity of the session. These mechanisms should be optimized and adapted for different scenarios in the network, whether the network is high loaded or there are a lot of users, they should guarantee accessibility and establishment of sessions, authentication, authorization, signaling and they need to provide reliable communication with corresponding latency, jitter, lost packets and information. The operator needs to choose the proper multi-carrier and inter-working strategy in order to build flexible network, [2-3], to have suitable load balance and smooth transition between the available technologies. Beside the challenge of the mobility and the handover inside the network or between other networks, on the market there are more and more new advanced and sophisticated mobile multimedia services that can be offered through the smart devices, which are more demanding in the process of provisioning of QoE. Additionally, constrains from some devices and the transmission channels can have direct impact and influence on the end user perception.

The subjective method is based on the end user experience and it depends by the users, it represents the individual user experience by using the services, [4-6]. Each user may have different expectations, technical knowledge, experience, feelings, thoughts, mood, etc. Quality of experience is the total picture and a grade for the end-to-end service delight perceived by the end user. The customers are not interested how the QoS technics are implemented, but they can only see the total performance provided by the mobile operator. The operator may use the customer's satisfaction as an indicator of whether they are doing things right. Usually the operators can evaluate user's satisfaction through user complaints or increase/decrease in revenue. Due to the subjectiveness of QoE as a metric that may depend on many factors, the best estimation may be measuring some of the dependences and evaluating them. Then the metric which represent the subjective degree of the quality can be calculated.

Successful implementation of the QoE management will fulfill user's requirements and expectations and make them satisfied, and that will open way for the users to buy and use new progressive services and allow further evolution of technologies. The right treat-ment of QoE is important for all players that are included in providing services, from vendors of telecommunication equipment, via network operators to service providers and players in differrent verticals. They are trying to maximize the end user experience with the highest acceptable quality of service, while they are minimizing their costs. Constant monitoring of the QoE should allow fixing problems on time, before the users can experience the negative effects. Successful maintenance of QoE brings advantage of attaining the existing users and attracting new one.

\section{QoE INDICATORS IN MOBILE NETWORKS}

\section{A). QoE for voice services}

The performance of the voice services can be measured under different criteria. Mean Opinion Score (MOS) is a measure for quality evaluation of the voice (Table 1) [7].

\section{Table 1}

MOS (Mean Opinion Score) values

\begin{tabular}{ccc}
\hline \hline MOS & Quality & Impairment \\
\hline 5 & Excellent & Imperceptible \\
4 & Good & Perceptible but not annoying \\
3 & Fair & Slightly annoying \\
2 & Poor & Annoying \\
1 & Bad & Very annoying \\
\hline \hline
\end{tabular}

During the test measurement, the test devices are running a script with appropriate language speech samples and according the POLQA algorithm the speech samples at the mobile originating and mobile terminating device are compared and MOS grade is generated [8-10]. In order to get the most accurate quality for the voice, the measurements should be performed with big number of samples during different loads in the network.

If the network supports VoLTE then we have voice over IP protocol and additional properties should be taken into consideration, [11-12]. In that manner, the end-to-end delay is time needed for one packet to be transferred from one user device to another through the LTE network. This delay depends on the performance of the network and the distance between the eNodeBs. In order to have ideal voice quality the time for end-to-end delay should be smaller than $50 \mathrm{~ms}$, for an average quality this value should be under $150 \mathrm{~ms}$. 
The packet loss is also important parameter. It displays how many of the packets snent did not reach the final destination. For real-time service the UDP protocol is typically used, therefore the packets cannot be transferred again. For ideal voice quality the lost packets should be less than $1 \%$, while for an average quality this value should be below $5 \%$.

Another parameter that may impact the voice quality is jitter. Jitter is the variation in the latency on the packet flow, indicating that the packets from the same flow need different times to arrive at the destination. For ideal voice quality jitter values should be under $20 \mathrm{~ms}$, while for an average quality the jitter values should be under $50 \mathrm{~ms}$.

\section{B) QoE for data services}

The QoE for the data services depends on a lot of parameters and indicators [13]. Although there is no specific standardized algorithm (as for voice), it is necessary to choose and measure the most important characteristics of the network and then estimate the quality. Nevertheless, besides having stable connection, fast transfer of data, and low latency, additional parameters should be measured which will indicate if the network is capable to handle the current most popular applications, social media, etc. Such parameters include: DL/UL data throughput, latency, number of transfers in specific time, then simultaneous transfers, Social Media, Web surfing, Audio/Video streaming, etc.

\section{QoE for data transfer}

The complexity of the networks, devices and services brings additional latency and non-reliability which can affect the user experience. Usually when the load in the network is the highest, then the user's dissatisfaction is the highest, for example the web page loading or the data transfer is very slow, which is limitation for some applications to be used in mobile environment.

The main factors that can affect the data transfer are:

- Unsuitable planned capacity, scheduling parameters or bad QoS implementation.

- Latency due to processing (including the server's processing time and queued tasks).

- Latency due to queuing or congestion, unsuitable buffer size.

- Latency due to propagation or low link speed.

- Degradation of the speed due to TCP mechanisms, active TCP sessions, size of the data, packet loss.

\section{QoE for web browsing}

When we talk about web browsing, we actually mean on the HTTP services, therefore the browsing process depends on the HTTP download speed and the latency of HTTP mechanisms. When the web browser is accessing a web page, first is using DNS for resolving and then establishes TCP connection in order to download the HTML content. After download of the HTML page, the browser also checks for all additional objects on that page to be downloaded, via the same HTTP connection, with HTTP 1.1 or HTTP 2.0 (all browsers have HTTP 1.1 since it is a standard from 1997, while not all browsers have HTTP 2.0 which is the last HTTP standard, completed in 2015 by the IETF - Internet Engineering Task Force). QoE during web browsing can be described with several parameters such as availability of the service, response time of the service, and the transfer time of the data. The latency is the time between the HTTP GET request message and the moment when the entire web page is loaded including all objects on it. Based on the measurement results (presented further in this paper), the desired response time is less than 2 seconds, acceptable response time is up to 4 seconds, while 10 seconds is the critical threshold to keep the user's attention.

\section{QoE for streaming}

Performance indicators for video streaming cannot be defined precisely, because they depend on various factors. Some factors inlcude the generation of mobile network we use (2G/3G/4G), [14-17], the network topology providing the streaming service, the type of content, the coding scheme, the capability of the devices, etc. The following performance indicators are the most critical for streaming and according to these values we can evaluate the quality of the streaming. The quality of the streaming can be evaluated according to the following performance indicators, which are most critical for streaming:

- The streaming service access time represents the time duration from streaming request to the start of the streaming;

- The buffering time can be analyzed in different stages during streaming: a) as the time from start of the initial buffering until the start of the stream, b) as the time from the start of the streaming until the first buffering, c) duration of the buffering or d) how many buffering events appeared during streaming;

- Video average resolution; 
- Number of freeze playback events, which are the most annoying factor.

\section{C) Crowdsourcing}

Crowdsourcing is the latest approach of collecting massive data which is used to estimate the user experience and the quality of the provided service, $[1,18]$. Crowdsourcing is a task which is predefined by some agent and later is distributed to the end user's devices. With permission of the users these tasks are activated and executed as background process which collect the data. The data is then sent to a central server where the results are processed. This methodology allows operators to extend and complement the scope of the measurements so they can estimate the QoE. Monitoring and the measurements of the network can be performed in a passive or active way.

During passive monitoring the traffic in the network is only monitored through additional integrated interfaces and later the analysis reports are sent to the corresponding processing server. Passive monitoring is usually performed at the core network or at the radio network controllers (if any).

Active monitoring is based on traffic injection in the mobile network and monitoring of the response of the network. Active measurements are performed on the user's equipment and they complement the drive test measurements in mobile networks. The main idea is that the smart phones should act like sensors distributed on specific geographical area and can monitor and test the radio access network. These smart phones will have the same target, they will run same tasks/applications and they will be coordinated by specific server. Example for this kind of applications is Speedtest by Ookla.

Advantages of crowdsourcing over the regular drive tests are less costs (maintenance and software upgrades is done by the owners of the device, no need to by additional test equipment), test of indoor and some specific scenarios, big number of devices included in the measurements, real-time operations, take less time to perform the measurements, display of real end user experience results.

Disadvantage of this type of measurement is that the application cannot access all network related parameters (type of wireless technology, signal strength and quality, Cell ID, LAC, information about carrier aggregation and MIMO usage, etc.). Additionally, the devices are not under some central authority, instead they are controlled by themselves. Due to such reasons one cannot verify if the results are reliable and accurate, because don't know the CPU usage, battery level, memory usage, and active background applications. Considering that the devices are for personal use sometimes the user doesn't want to download this kind of applications or won't accept all the terms and conditions by the application so the application won't access all the necessary parameters (e.g., GPS information). Another challenge is that different users have different tariff models and packages which limit the uplink/downlink volumes of data or throughput speeds. All these factors can lead to unreal picture about the performance of the network and the user experience.

\section{RESULTS AND ANALYSIS}

In this section we overview the details and analysis of the results of the conducted field drive tests for the mobile networks. The mobile networks are ranked as outstanding in their performance according the $\mathrm{P} 3$ group. The results will be compared and presented for the period of last 3 years where there is an indication the trend of improvement and implementation of the latest technologies.

\section{A) Equipment and test scenario}

The measurement equipment and the measurement configuration used is as follows:

Two devices were used for voice measurment (LTE Category 9 and LTE Category 6), one is configured as mobile originating and the other as mobile terminating. It should be noted that the mobile network does not support VoLTE, so the phones are set in free mode ( $3 \mathrm{G} / 2 \mathrm{G}$ mode). The signal of one of the phones is additionally attenuated in order to test the inter-operability during weak coverage and the voice quality under these conditions. There is automatic script for starting and answering calls and there is a pause between two calls in a row.

The data measurements were conducted using LTE Category 16 which supports carrier aggregation and MIMO up to $4 \times 4,256$ QAM in downlink and 64 QAM in uplink. The phone is set in free mode ( $4 \mathrm{G} / 3 \mathrm{G} / 2 \mathrm{G}$ mode).

The script is performing the following steps [18]:

- HTTP download multi-socket data stream,

- HTTP upload multi-socket data stream,

- HTTP download of fixed file size,

- HTTP upload of fixed file size,

- Web Browsing (ETSI Kepler page),

- Top 10 Live Web Page browsing, 
- YouTube Streaming,

- ICMP PING.

The test equipment can be placed into one test car or in two cars which during the test will keep certain distance.

Before the test are started, well defined routes and regions are chosen, this depends by what needs to be achieved and what is the target of the specific project. Generally is to check the present user experience and performance, to collect data and compare it later with next round data to see if there is some benefit and improvement, also to compare the performance of the competitor's mobile network user experience.

In this paper, the results are collected from optimization campaign where the present user experience is checked and in same time compared with the competitor's performance. From the results can be seen that both operators are improving and upgrading their networks in different periods and trying to achieve the best user experience.
Since Macedonia is small country almost every cities are tested and main highways are selected. In fact the test scenario later during optimization can be divided on more parts: dense-urban, urban, rural and highways. Each scenario is properly treated and corresponding measures are applied.

\section{B) Results and analysis from voice measurement}

Considering that VoLTE has not yet been introduced at the time of measurements, if the mobile devices are set to work in free mode, they are camping on LTE technology and during voice calls they perform CSFB (Circuit Switched FallBack) to 3G or in some cases to $2 \mathrm{G}$ technology.

Voice measurement script is given in Figure 1. From the latest results the drop call rate is approximately $0.1 \%$ for both operators which is very good result and brings less annoying experience. The number of call setup failures and missed calls events is very low.

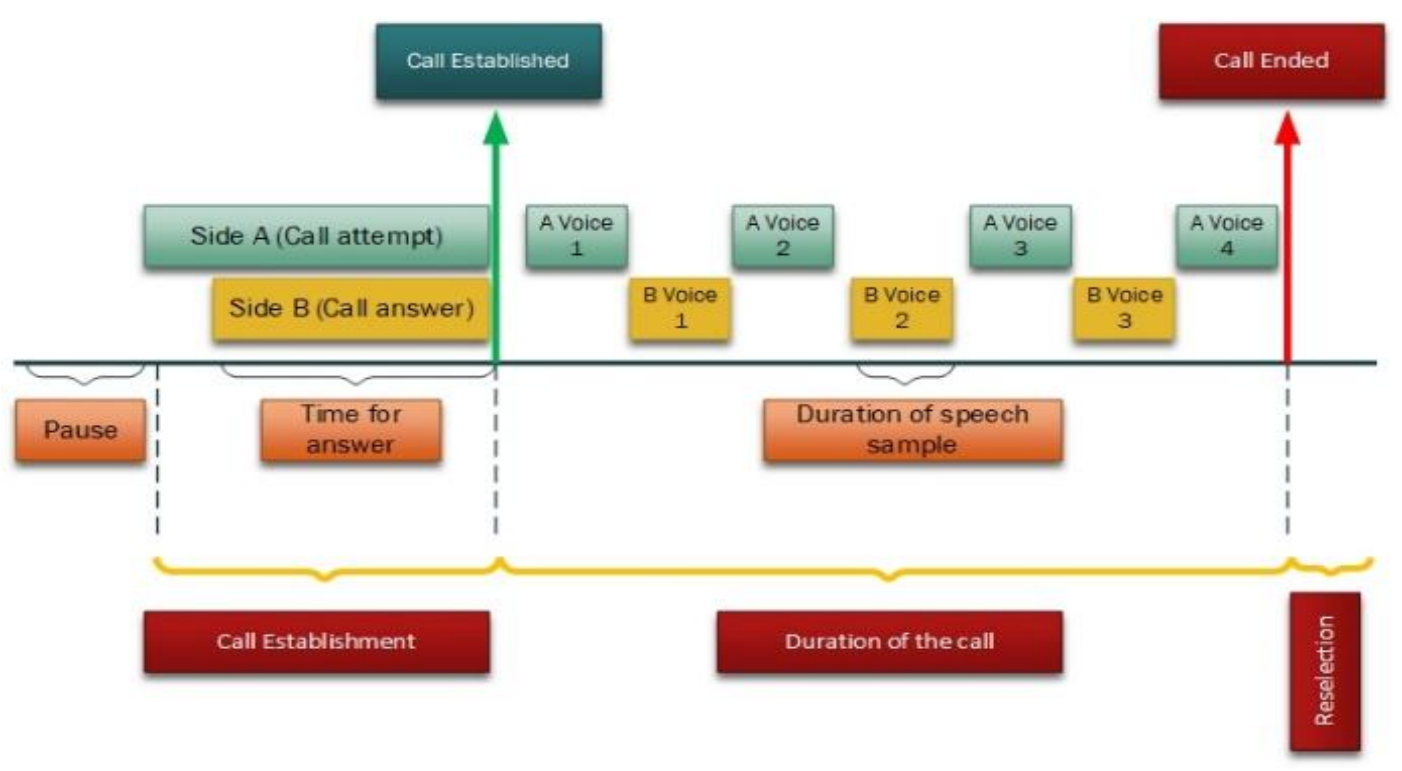

Fig. 1. Voice measurement script

If we compare the call setup time during CS (Circuit Switched) sessions in the period of the last 2-3 years, there is a noticable trend of call setup time reduction and improvement for both operators, from average $7 \mathrm{~s}$ to $4.5 \mathrm{~s}$, as shown on Figure 2.

The trend of improving of the voice quality is also visible. The average values for MOS from 3.67 and 2.83 in September 2016 improve to 3.85 and 3.86 in December 2018 for mobile operator 1 and mobile operator 2, respectively, shown in Figure 3.

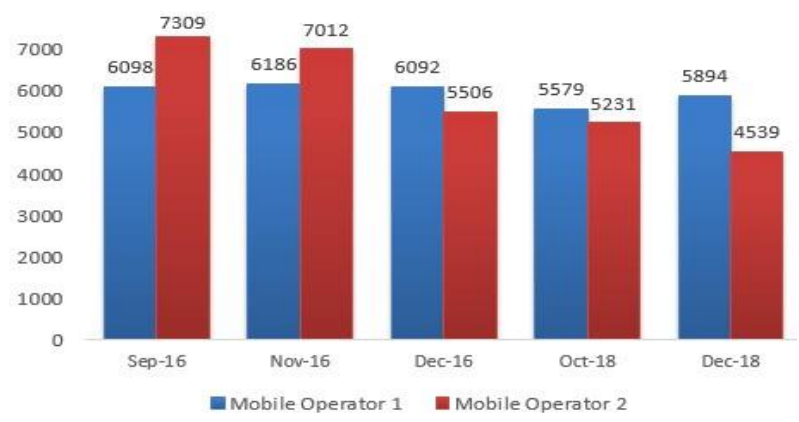

Fig. 2. Call setup time (ms) 


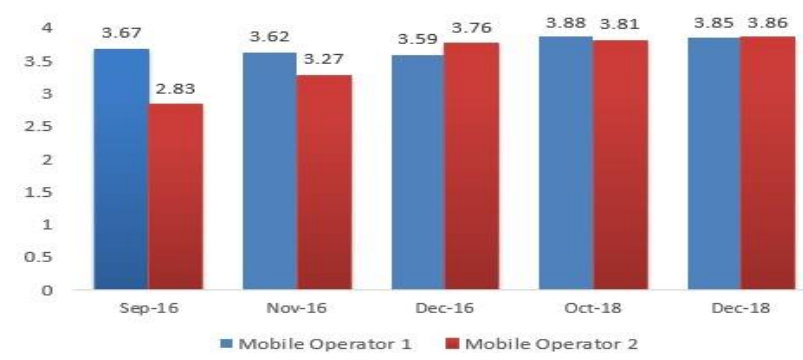

Fig. 3. MOS value for MO CS device

From the analysis of the voice performance, improvement of the KPI mostly depends from the strength and quality of the signal. If we have good radio conditions and coverage the risk of unwanted events like dropped calls, long call setup time, low MOS, is lower. It is always important during the optimization project for operators first to start and focus on the RF optimization. The fine tuning is done later using parameters and advanced settings for specific scenarios.

Example of critical areas:

- Weak coverage area is considered an area where the pilot's power is between the lowest threshold for accessing the network and the lowest value which needs to be fulfilled to ensure good coverage.

- Areas with pilot pollution represent places in which there is no dominant cell and the serving cell is changing very frequently. In these cases, there is a lot of unnecessary handovers, efficiency of the system decreases, and the probability for unsustainable and dropped calls increases. In these areas, typically there are three or more cells with low strength and quality signal.

Especially for UMTS and LTE it is very important to check and verify the propagation of the signal from the cells because these technologies are sensitive from interference cause by overshooting. This means that the coverage from specific cell is very far and the broadcasted signal can interfere with the other cells which need to cover the interfered area.

Beside the radio conditions another important part is the network strategy. It is essential to adjust the mobility events and the inter-working strategy. Under certain thresholds the UE (User Equipment) should handover between the carriers under the same technology or handover between different technologies. Proper handover thresholds will allow consistency and continuity of the service. In the process of designing the network, certain thresholds are set and can be later tuned in accordance with the monitoring of the traffic and active UEs on the available carriers or technologies.

During high load events, the network should be equipped with mechanisms that will balance the load and maintain normal work of the cell. High load can increase the uplink interference and reduce the capacity, which can decrease the accessibility to the cell and affect the user experience.

The samples distribution (MOS and call setup time) is given in Figure 4. Then, Figures 5 and 6 show the measured samples distribution. For MOS the maximum achieved value is 4.1 , while the shortest call setup time is 3.4 seconds. Depending on coverage and network load status these values can be different.

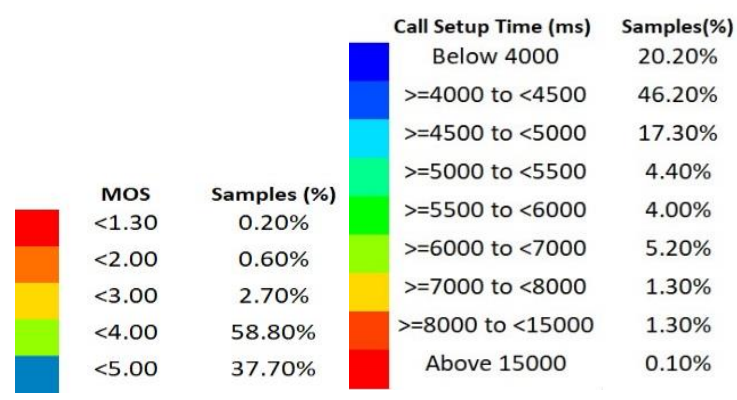

Fig. 4. Samples distribution (MOS and call setup time)

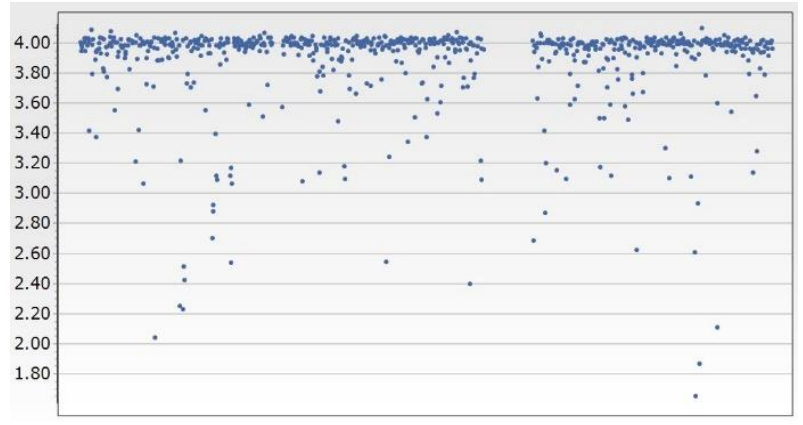

Fig. 5. MOS samples distribution

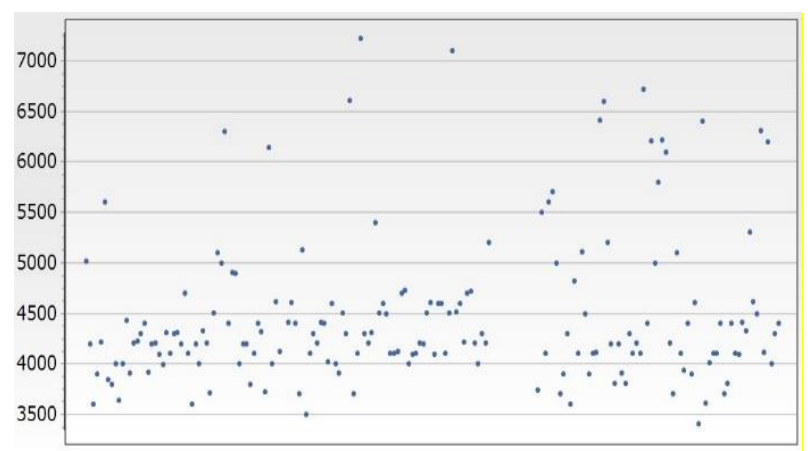

Fig. 6. Call setup time samples distribution (ms) 
Improvement of the voice performances can certainly be done with deployment of VoLTE which allows voice service with high quality voice due to enabling of HD voice codecs, short call setup time and higher utilization of the bandwidth (due to use of LTE access technology which has higher spectrum efficiency than WCDMA in $3 \mathrm{G}$ networks). Instead of using CSFB procedure towards different technologies, the UEs can establish call through the LTE technology. The call setup time is approximately $\sim 1$ second comparing to current $\sim 5$ seconds for establishing call. New super wideband codecs are introduced which allow super HD voice, shown in Table 2.

Table 2

Voice codecs

\begin{tabular}{lcccc}
\hline \hline Codec name & Year & $\begin{array}{c}\text { Audio } \\
\text { Bandwidth }\end{array}$ & Technology & $\begin{array}{c}\text { Bitrates } \\
\text { Kbps }\end{array}$ \\
\hline $\begin{array}{l}\text { Enhanced Full } \\
\text { Rate (EFR) }\end{array}$ & 1996 & $\begin{array}{c}\text { Narrow } \\
\text { band }\end{array}$ & $2 \mathrm{G}$ & 12.2 \\
$\begin{array}{l}\text { AMR } \\
\text { Narrowband } \\
\text { (AMR-NB) }\end{array}$ & 1999 & $\begin{array}{c}\text { Narrow } \\
\text { band }\end{array}$ & $3 \mathrm{G} / 4 \mathrm{G}$ & $4.72-12.2$ \\
$\begin{array}{l}\text { AMR Wideband } \\
\text { (AMR-WB) }\end{array}$ & 2001 & Wide band & $\begin{array}{c}\text { HD voice } \\
3 \mathrm{G} / 4 \mathrm{G}\end{array}$ & $6.6-23.85$ \\
$\begin{array}{l}\text { Extended } \\
\text { AMR-WB } \\
\text { (AMR-WB+) }\end{array}$ & 2004 & $\begin{array}{c}\text { Full band } \\
\text { Full HD } \\
\text { voice }\end{array}$ & $6-48$ \\
$\begin{array}{l}\text { Enhanced Voice } \\
\text { Service (EVS) }\end{array}$ & 2014 & $\begin{array}{c}\text { Super wide } \\
\text { band }\end{array}$ & $\begin{array}{c}\text { Super HD } \\
\text { voice 4G }\end{array}$ & $5.9-128$ \\
\hline \hline
\end{tabular}

These super codecs support wider audio bandwidth which allows better understanding, more natural sound, comfortable and transparent. This contributes to achieve high MOS value $\left(4.0^{+}\right)$.

Mechanisms like semi-persistent scheduling (SPS), TTI-Bundling, RoHC, RLC segmentation bring higher capacity, bigger coverage, less dropped calls and higher rate of successfully established calls.

SPS allows reduction of the utilization of the $\mathrm{PDCCH}$, this brings more users to access the cell. PDCCH carries the allocation information for both uplink and downlink shared channels. Each allocation is transferred as downlink control information (DCI), since PDCCH has limited size, the number of carried DCI is also limited. Without increasing of PDCCH channels and deployment of SPS the UE is pre-configured by the eNodeB with SPS and periodicity. And, the same configuration remains fixed for each radio resource allocation (e.g., resource block assignment, Modulation and Coding Scheme - MCS, etc).

TTI Bundling brings improvement of the uplink coverage and balance between the uplink and downlink coverage. Main reason for the disbalance between uplink and downlink is the limited transmission power of the UE ( $200 \mathrm{~mW}$ or $23 \mathrm{dBm})$. If the UE is located on cell edge, its power may not be sufficient to transmit VoIP packet (in the uplink) during one TTI period. Therefore, when the SINR is very low and the BLER (Block Error Ratio) is high, the link adaptation can handle the problem even with the lowest allocation of MCS or PRB. If TTI bundling is activated more transport block are sent consecutively without receiving HARQ ACK/NACK. This allows more power allocation per packet and avoiding additional overhead from packet segmentation.

RoHC mechanism performs compression of the headers of the packet. With compression of the voice packets the user plane traffic is decreased in the air interface. Unnecessarily used bandwidth becomes available which results in lower load and smaller utilization of PRB resources. That brings capacity and coverage benefit.

RLC segmentation brings positive effect when the UEs are positioned at the cell edge. As mentioned before, due to power limitation and due to poor radio conditions in order to maintain the communication, the uplink scheduler will start with packet segmentation. Due to RLC segmentation the payload bits per transmission are decreased, but on the other hand power per bit is increased. Each segment is labeled with RLC/MAC header and CRC checksum and it is sent through different transport blocks, however with an additional overhead. This way we have more energy per voice packet which brings increase in the coverage.

\section{C) Results from data measurements}

The mobile operators in the measurement scenarios are marked as Mobile Operator 1 and Mobile Operator 2. Obtained results from data measurements show similar downlink and uplink speeds for both mobile operators (Table 3 and Table 4). The average speeds in downlink are $\sim 55 \mathrm{Mbps}$ and the average speeds in uplink are $\sim 30 \mathrm{Mbps}$ calculated for both urban and road scenarios. In the cities the downlink speeds are higher comparing to the roads, this is due to using of additional carriers, technics like carrier aggregation and on some places is deployed $4 \times 4$ MIMO. The maximum speeds can reach up to $200 \mathrm{Mbps}$ (Figure 7). 


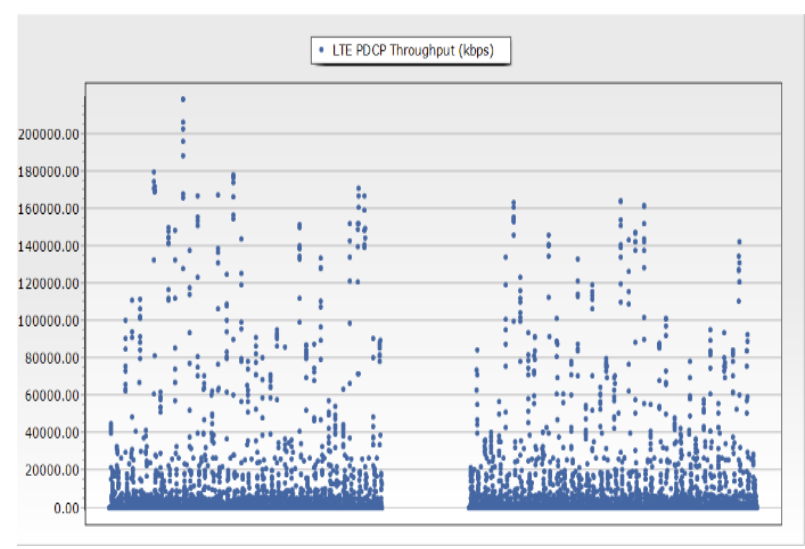

Fig. 7. LTE UE PDCP throughput in downlink (kbps)

Because the trend of mobile data traffic growth and development of new applications which have strict requirements regarding throughput and latency, operators should constantly consider of adding more capacity in the mobile network. Beside implementation of additional carriers and extra frequency spectrum, MIMO with more layers can improve spectral efficiency and the radio link status during bad radio conditions.

Ta b le 3

Speed test in DL and UL based on time duration of the download

\begin{tabular}{|c|c|c|c|}
\hline \multirow[b]{2}{*}{ Operator } & \multicolumn{3}{|c|}{ FTP file DL/UL 7s } \\
\hline & & DL 7s & UL 7s \\
\hline \multirow{3}{*}{$\begin{array}{c}\text { Mobile } \\
\text { operator } 1\end{array}$} & Attempts & 580 & 570 \\
\hline & End & 580 & 570 \\
\hline & Throughput & 48271.12359 & 30179.18569 \\
\hline \multirow{3}{*}{$\begin{array}{c}\text { Mobile } \\
\text { operator } 2\end{array}$} & Attempts & 502 & 534 \\
\hline & End & 502 & 534 \\
\hline & Throughput & 54352.3989 & 31054.23389 \\
\hline
\end{tabular}

Table 4

Speed test in DL and UL based

\begin{tabular}{cccc}
\hline \hline & & FTP file & DL 3MB / UL 1MB \\
Operator & & DL 3MB & UL 1MB \\
\hline \multirow{2}{*}{ Mobile } & Attempts & 568 & 563 \\
operator 1 & End & 554 & 555 \\
& Task time & 1.823681 & 2.07802 \\
\hline \multirow{3}{*}{ Mobile } & Attempts & 489 & 488 \\
Operator 2 & End & 485 & 480 \\
& Task time & 1.190726 & 1.60601 \\
\hline \hline
\end{tabular}

Implementation of $4 \times 4 \mathrm{MIMO}$ can bring significant improvement of the quality of the signal and the throughput in the cell. The speed test results from the test conducted in lab conditions are shown in Figure 8 and the maximum speed achieved was around $650 \mathrm{Mbps}$ on the MAC (Medium Access Control) layer. For this test case 2 carriers where used, $20 \mathrm{MHz}$ on $1800 \mathrm{MHz}$ band and $15 \mathrm{MHz}$ on $2100 \mathrm{MHz}$ band. The test was performed in perfect (ideal) radio conditions. The CQI (Channel Quality Indicator) value reported from the UE was $\sim 15$ (maximum), according this the MCS values were 27 28 (maximum 28), therefore 256 QAM modulation was used. During the test the UE allocates the total bandwidth from the 2 carriers and carrier aggregation feature is enabled. Used transmission mode is TM4 (RANK4) with spatial multiplexing.

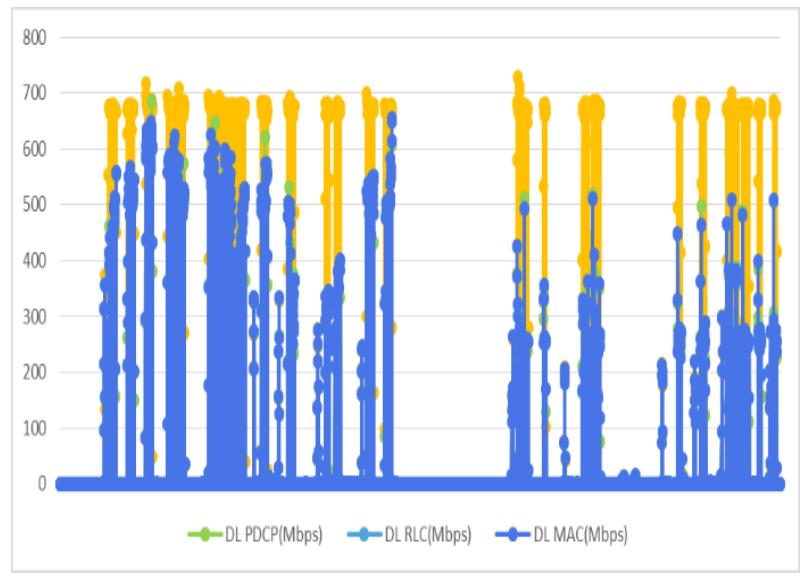

Fig. 8. $4 \times 4$ MIMO lab test throughput result

Additionally, when upgrade from lower to higher rank modulations is enabled, for example from 64 QAM to 256 QAM, the radius of the cell might be decreased due to power limitation during utilization of 256 QAM, respectively additional power should be set on cell level. Also coverage from neighboring cells should be checked and the top cells strong interferers must be removed in order to achieve clear signal and higher utilization of 256 QAM to be achieved.

After the implementation in a real-case scenario in a commercial mobile network, depending upon the coverage area, cell radius, and network load, several improvements are achieved.

On the dense urban site with smaller coverage, Figure 9 shows the improvement of coverage CQI index from 10 to $11 \sim 12$. More resource blocks are scheduled with CQI 15 (Figure 10), which brings use of higher modulation schemes (Figure 11), increase of the utilization ratio of 256 QAM and 
higher throughput (Figure 12). In cases with previously measured had poor radio conditions, use of the spatial multiplexing transmission mode gives better results than the transmission mode with diversity (Figure 13). Also, the BLER rate is decreased for this type of sites (Figure 14).

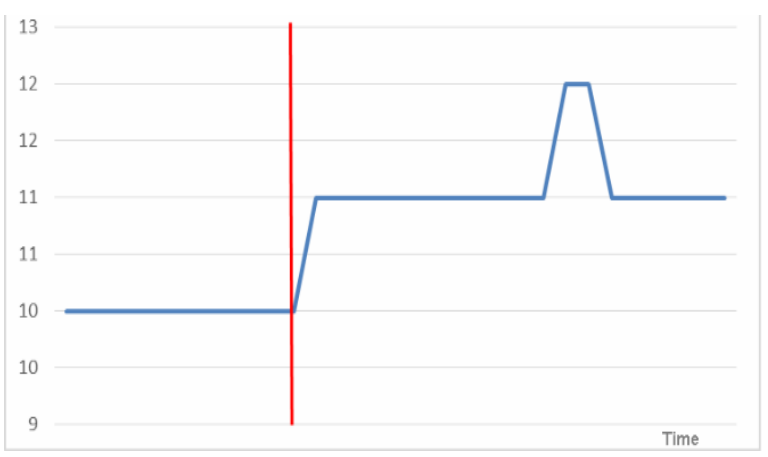

Fig. 9. CQI tndex improvement (before - left from the red line, and after optimization - right from the red line)

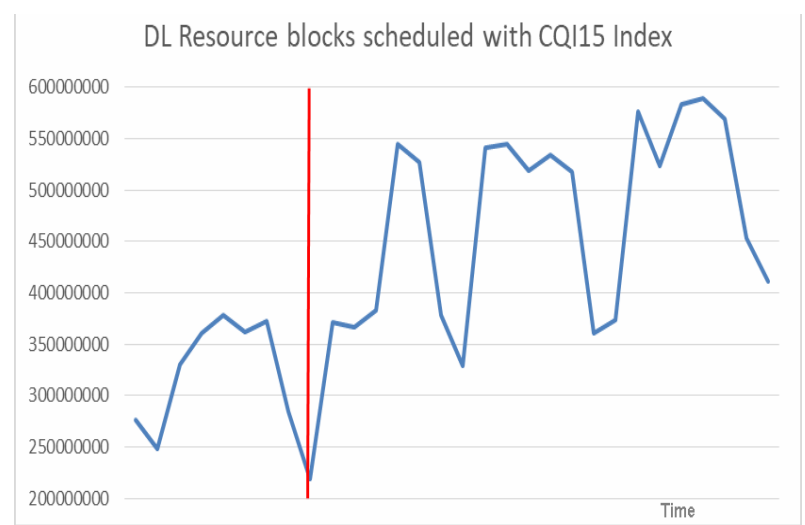

Fig. 10 Resource blocks scheduled with CQI15 (before the change - left from the red line, and after the change - right from the red line)

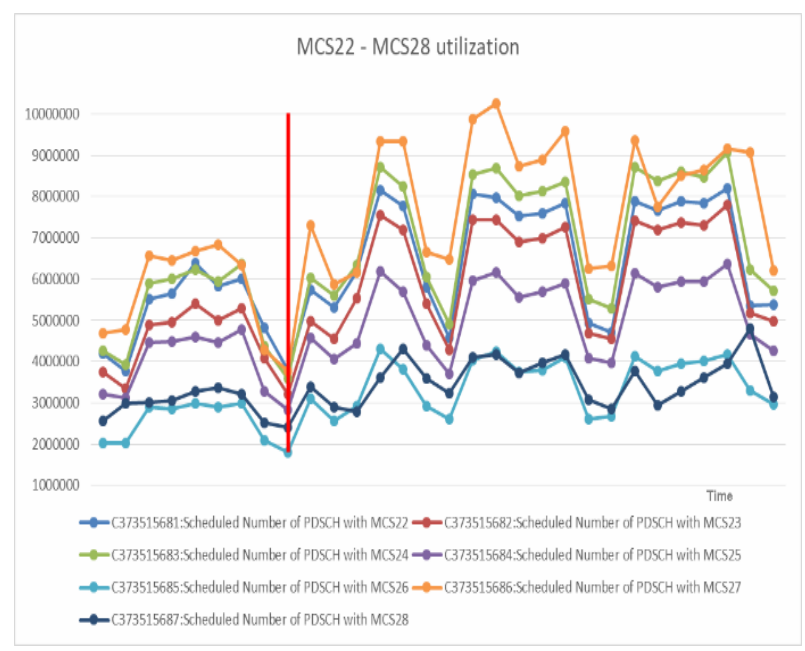

Fig. 11. Higher utilization of the higher coding schemes

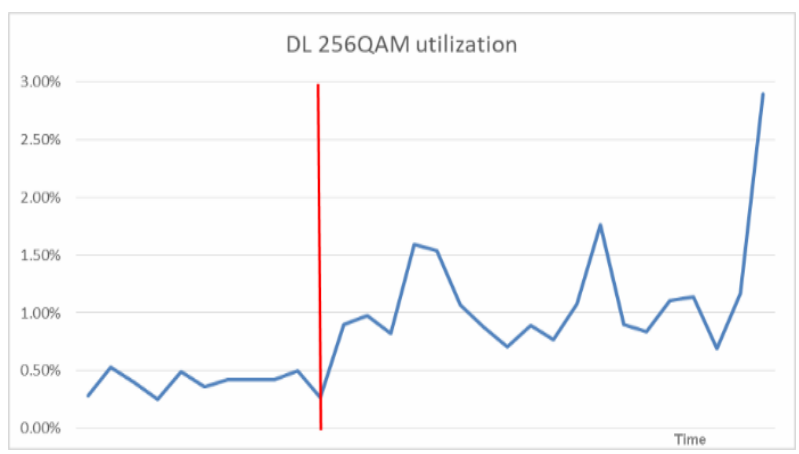

Fig. 12. Utilization of 256 QAM in downlink

Type of TM4 transmission

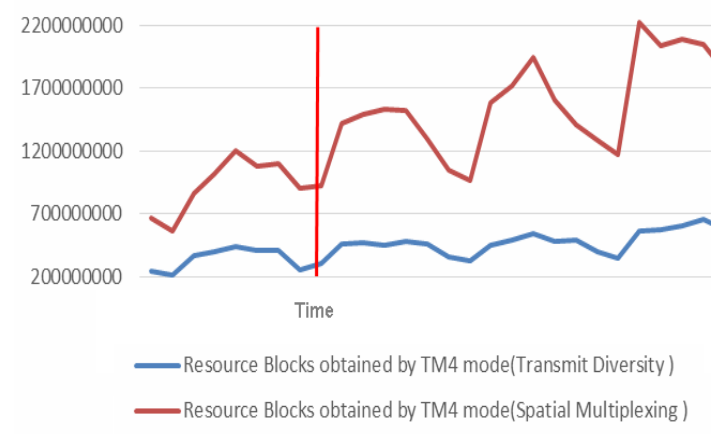

Fig. 13. Increase of spatial multiplexing mode

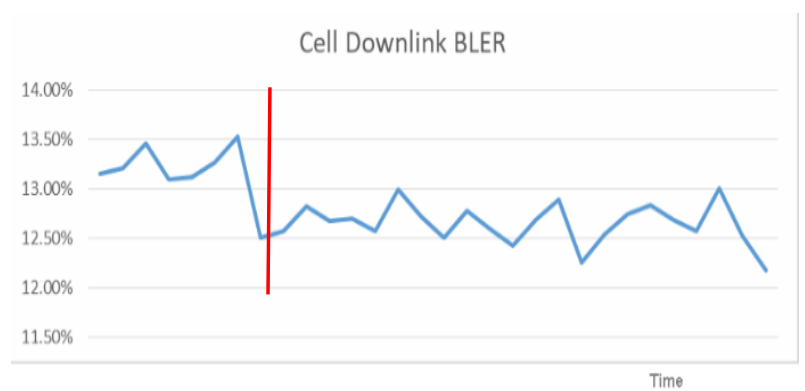

Fig. 14. Block error rate in downlink

The changes result in improvement of the throughput on a cell level, also the transfer speed to the UE brings benefit for all type of different data services through the mobile Internet access (faster data transfers, shorter download time for web, faster loading of HD videos, etc.).

The latency for establishing different services is also very important. It may depend on the design of the mobile network, number of hops (e.g., in the core network) and the distance between the network elements. Regarding the radio interface proper scheduling scheme need to be implemented in order to decrease the latency. With some adapted scheduling schemes, the frequency of communication between the UE and the eNodeB can be controlled. 
Proper scheduling allows efficient link adaptation, rate control, packet scheduling, resource assignment, and power control. With choice of certain parameters it can be enabled specific number of users to be scheduled, but in this way the cell capacity for the active users can be decreased while latency can be improved.

Table 5 shows test results for web browsing of the most popular web pages at the present time. For web browsing (Figure 15), the following procedures can be optimized. For instace, after the first DNS response, the IP after receiving DNS response can be cached so the next time the UE will automatically use the needed IP address and this will save the DNS look up time. With optimizing the RTT the latency during download of each object will be decreased which will bring lower web loading time.

Table 5

Web browsing: testing the popular web sites

\begin{tabular}{clccccccc}
\hline \hline \multirow{2}{*}{ Operator } & & \multicolumn{4}{c}{ Web Loading } & & \multicolumn{3}{c}{ Static } \\
& & Daily.mk & Ebay & Google & Imdb & Microsoft & Time.mk & ETS \\
\hline $\begin{array}{c}\text { Mobile } \\
\text { operator 1 }\end{array}$ & Attemps & 290 & 283 & 2.83 & 278 & 218 & 289 & 1147 \\
& End & 289 & 282 & 2.82 & 269 & 277 & 289 & 1146 \\
& Download time (s) & 6.45 & 3.1 & 1.21 & 7.62 & 2.72 & 3 & 1.98 \\
$\begin{array}{c}\text { Mobile } \\
\text { operator 2 2 }\end{array}$ & Attremps & 2.48 & 243 & 2.47 & 240 & 241 & 248 & 990 \\
& End & 2.46 & 242 & 246 & 240 & 236 & 247 & 981 \\
& Download time (s) & 5.98 & 2,73 & 1.13 & 6,64 & 2.43 & 3.6 & 2.15 \\
\hline \hline
\end{tabular}

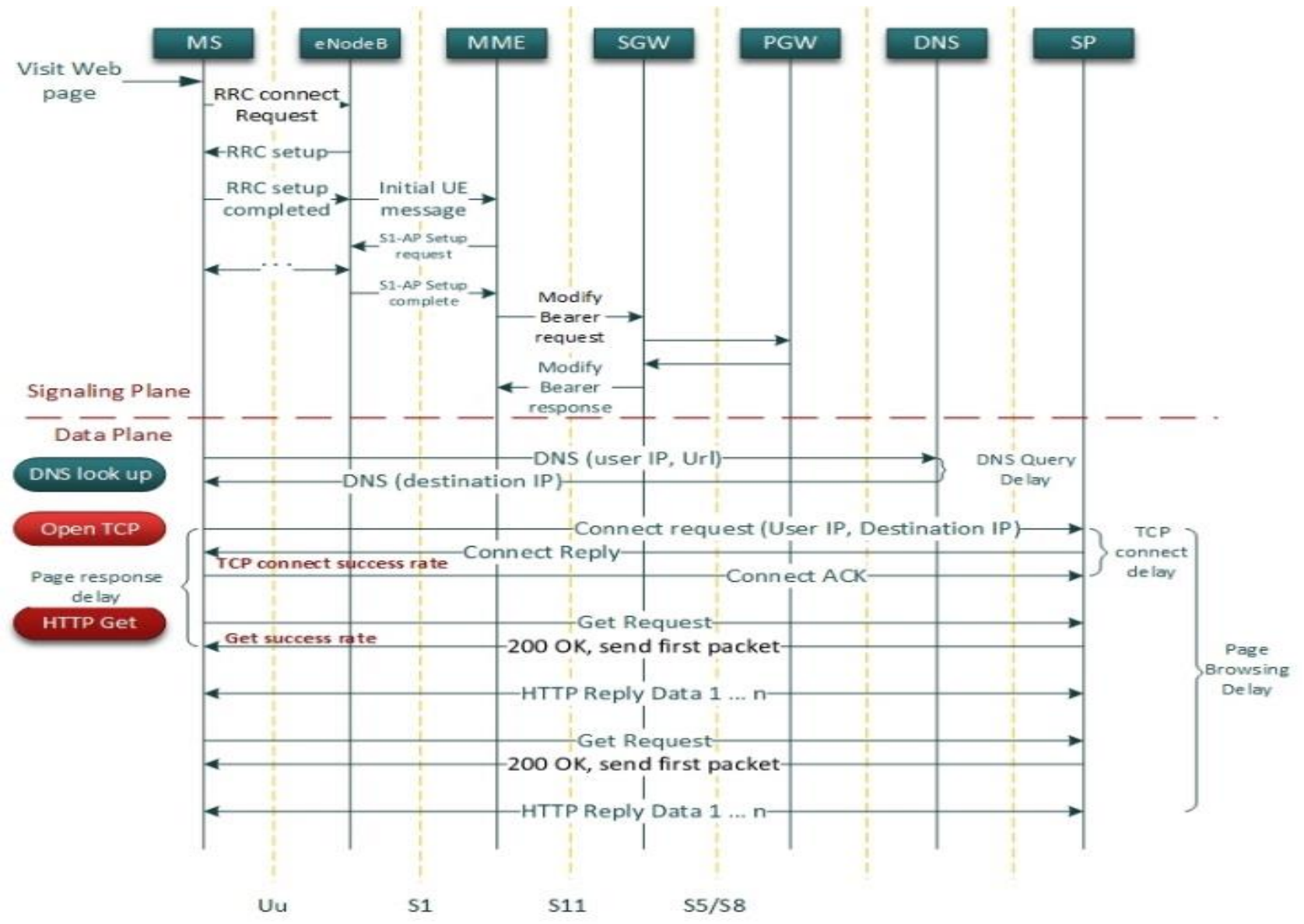

Fig. 15. Procedures during web browsing 


\section{CONCLUSION}

This paper describes the evaluation of the QoS and QoE of the voice and data services of the current mobile networks. It gives analysis of the measured performance indicators and provides proposals for further deployment of features and techniques so as to be achieved completion of the 4G technology. Following and repeating the steps of this kind of optimization campaign will lead to maximal utilization of the potentials and performance offered by $4 \mathrm{G}$ technologies.

However, despite the constant and dedicated work to improve QoE, there are certain requirements from specific applications that cannot be met according to the capabilities of the currently available technology.

With the next generation networks $(5 \mathrm{G})$ are defined new boundaries and targets, much higher throughput and speeds up to $10 \mathrm{Gbps}$ (eMBB) needed for new type of services like Virtual reality and Augmented reality, much higher reliability and lower latency $(1 \mathrm{~ms})$ for satisfying the remote services like assisted driving or remote management and control in the traditional industries such as automotive, health, energy and urban municipal systems. Additionally, big number of connections, 1 million per $\mathrm{km}^{2}$ for implementation of Internet of Everything (IoE). The emergence of smart society (smart city, smart monitoring, smart home, smart parking etc.) is a new challenge that requires a large number of connections for the collection of a large amount of data, their processing and of course the functioning of the system itself.

Therefore, mobile operators should timely monitor the trend and respond appropriately to such challenges and provide satisfactory user experience for such services.

$5 \mathrm{G}$ is in fact the beginning of the digitization promotion, starting from personal entertainment and collaborative work on distance to interconnection of society and entrance of telecom operators and service providers into many different verticals i.e. new market sectors. Digitization creates enormous opportunities for the mobile telecommunica- tions but poses strong challenges to mobile communication technologies regarding the $Q o S$ and $Q o E$, especially in respect to real-time and future critical services through the mobile networks.

\section{REFERENCES}

[1] Janevski, T.: QoS for Fixed and Mobile Ultra-Broadband, Wiley (Wiley - IEEE series), UK, 2019.

[2] Janevski, T.: Internet Technologies for Fixed and Mobile Networks, Artech House, USA, 2015.

[3] Janevski, T., NGN Architectures, Protocols and Services, Wiley, UK, 2014.

[4] ITU-T Recommendation G.1011, "Reference guide to quality of experience assessment methodologies", July 2016.

[5] ITU-T Recommendation E.802 Amendment 1, "Framework and methodologies for the determination and application of QoS parameters", March 2017.

[6] ITU-T Recommendation Y.1545.1, "Framework for monitoring the quality of service of IP network services", March 2017.

[7] TU-T Recommendation P.800.1, "Mean opinion score (MOS) terminology", July 2016.

[8] ITU-T Recommendation P.800.2, "Mean opinion score interpretation and reporting", July 2016.

[9] ITU-T Recommendation P.862, "Perceptual evaluation of speech quality (PESQ): An objective method for end-to-end speech quality assessment of narrow-band telephone networks and speech codecs", February 2001

[10] ITU-T Recommendation P.863, "Perceptual objective listening quality prediction", March 2018.

[11] ITU-T Recommendation G.1028, "End-to-end quality of service for voice over 4G mobile networks", April 2016.

[12] ITU-T Recommendation G.107, "The E-model: a computational model for use in transmission planning", June 2015.

[13] ITU-T Recommendation E.804, "Quality of service aspects for popular services in mobile networks", February 2014.

[14] ITU-T Recommendation, Y.1540, "Framework for monitoring the quality of service of IP network services", July 2016.

[15] Leading 5G Innovations, ZTE, 2017.

[16] 3GPP TS 23.503 V15.1.0, "Policy and charging control framework for the 5GsSystem; Stage 2 (Release 15)", March 2018

[17] 3GPP TS 23.501 V15.1.0, "System architecture for the 5G system; Stage 2 (Release 15)", March 2018.

[18] ITU-D, “Quality of Service Manual”, 2017. 
